\title{
Stability and transformation of metabolic syndrome in adolescents A prospective assessment in relation to the change of metabolic risk factors
}

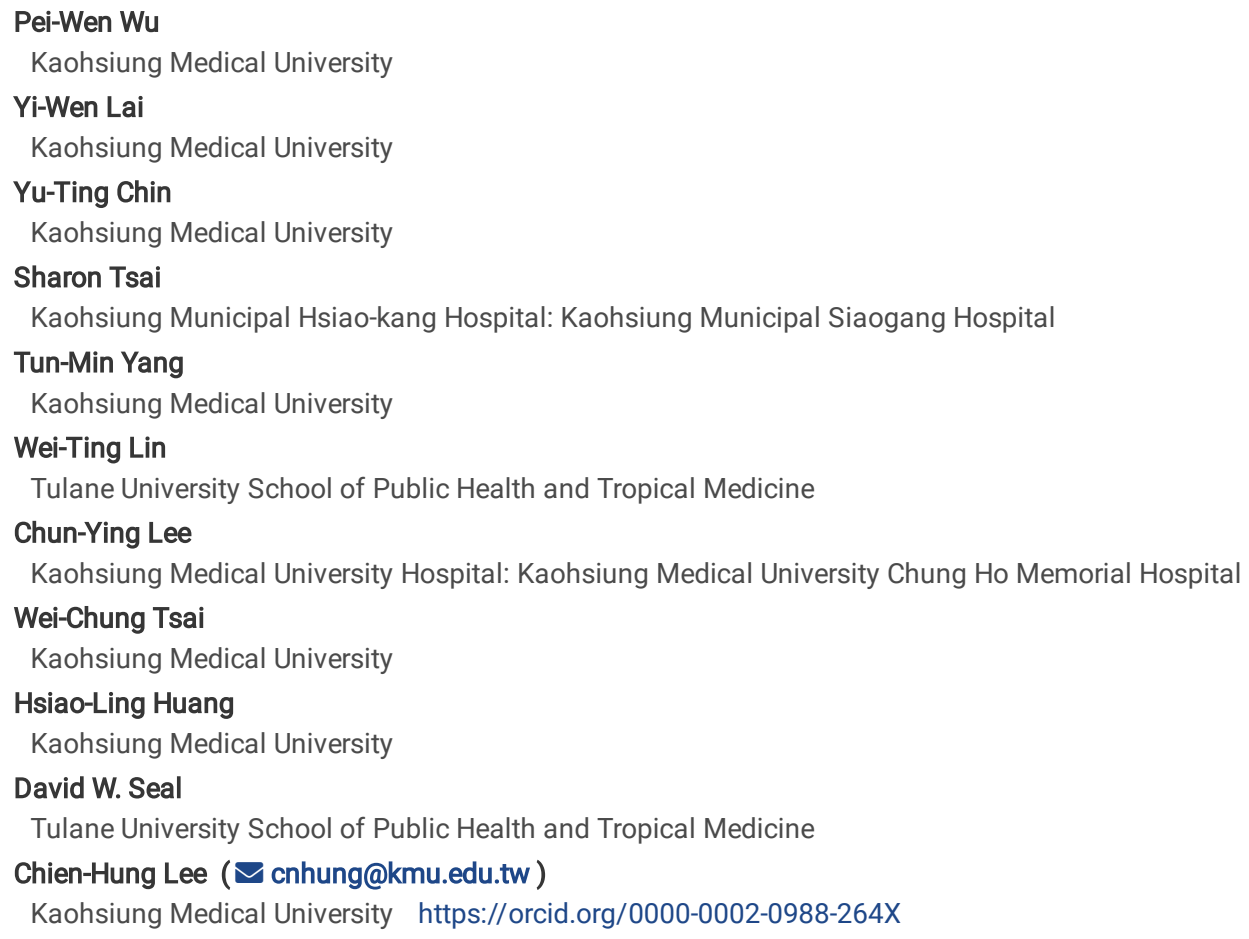




\section{Abstract \\ Background}

Underlying pathophysiological mechanisms drive excessive clustering of cardiometabolic risk factors, causing metabolic syndrome (MetS). However, MetS status may transform as adolescents transition to young adulthood. This study evaluated the latent clustering structure and its stability for MetS during adolescence and investigated the determinants for MetS transformation over 2 years of follow-up.

\section{Methods}

A community-based representative adolescent cohort $(n=1516)$ was evaluated for MetS using four diagnostic criteria and followed for 2.2 years to identify new-onset MetS. Factor analysis and polytomous logistic regression were separately applied to investigate the latent clustering structure for MetS and the relationship between changes in metabolic risk factors and transformations in MetS status.

\section{Results}

The clustering pattern of cardiometabolic parameters was comparable at baseline and follow-up surveys; both comprised a fat-blood pressure-glucose three-factor structure (total variance explained: $68.8 \%$ and $69.7 \%$, respectively). Among adolescents who were MetS-negative at baseline, $3.2 \%-4.4 \%$ had incident MetS after 2 years. Among adolescents who were MetS-positive at baseline, $52.0 \%-61.9 \%$ experienced MetS remission, and $38.1 \%-48.0 \%$ experienced MetS persistence. Increased systolic blood pressure (SBP) was associated with a higher risk of MetS incidence, and decreased SBP, triglycerides, and glucose levels were associated with MetS remission. Compared with adolescents with a normal metabolic status at baseline, those having an initial abnormal status in the five MetS components all had greater risks for persistent metabolic abnormality 2 years later, with abdominal obesity and increased triglycerides rendering a 15.0- and 5.7-fold risk, respectively.

\section{Conclusions}

The structure of cardiometabolic parameter clustering for MetS is stable during adolescence. Changes in metabolic risk factors affect typological transformation of adolescent MetS. Abnormal MetS components have a high probability of persisting. Early identification of each abnormal component and attendant intervention are vital in adolescents to minimize the future risk of cardiometabolic disorders.

\section{Introduction}

The pathogenesis of cardiovascular disease starts in childhood, when cardiometabolic risk factors are first observed [1]. In adolescents, metabolic syndrome (MetS) - a syndrome involving the clustering of abdominal obesity, hypertriglyceridemia, high fasting plasma glucose (FPG), low high-density lipoprotein cholesterol (HDL-C), and elevated blood pressure (BP) -is a vital risk marker for future cardiometabolic disease [2]. Longitudinal studies have demonstrated that childhood MetS is associated with a 2.0-2.9-fold risk for subclinical atherosclerosis, 2.3-11.5-fold risk for type 2 diabetes mellitus (T2DM), and 14.6-fold risk for cardiovascular disease after $14-30$ years [3-5].

The clustering of cardiometabolic risk factors exceeds what should be observed by chance aggregation, indicating the presence of common underlying pathophysiological mechanisms [2, 6, 7]. Accordingly, the questions of what cardiometabolic factor clustering structure reflect the latent pathogenic mechanisms and whether the clusters retain stable through growth stages in adolescents remain to be answered. An individual's MetS status may change from adolescence to young adulthood [8, 9]. One longitudinal study following adolescents up to adulthood revealed that $76.9 \%$ of the adolescents never had MetS, $16.4 \%$ had incident MetS, 5.7\% experienced unstable/remitted MetS, and 1.1\% had persistent MetS [9]. However, the typological changes in MetS status and their stability during adolescence remains unclear. A comparison of MetS transformation using diverse MetS diagnostic criteria may help clarify this.

Prospective investigations have observed that 3.8\%-5.2\% of MetS-negative adolescents (i.e., individuals aged 12-19 years) developed new MetS after 3 years; by contrast, $48.6 \%-56.1 \%$ of MetS-positive adolescents achieved remission 3 years later, and in $43.9 \%-51.4 \%$ of MetS-positive adolescents, MetS persisted [8]. If the structure of cardiometabolic parameter clustering for MetS is stable over adolescent growth, an investigation into the effect of metabolic risk determinants on typological transformation of adolescent MetS is warranted. In cross-sectional studies involving adolescents, metabolic risk factors have been observed to occur in childhood, but whether and to what extent they persist is unknown [10-13]. Insights into the persistence of metabolic risk factors and how they contribute to typological change of MetS can help create effective strategies for preventing MetS, increasing remission, and managing persistent MetS.

In a nationwide survey conducted in 2010-2011 in Taiwan, the prevalence of adolescent MetS, as defined by the Taiwan Pediatric Association (TPA) and International Diabetes Federation (IDF) diagnostic criteria, was $4.1 \%$ and $3.0 \%$, respectively, with $22.1 \%, 12.3 \%-19.3 \%$, and $17.7 \%-18.1 \%$ of adolescents having increased FPG, low HDL-C, and abdominal obesity, respectively [14]. Continuously monitoring and assessing the clustering of MetS risk factors and their impact on adolescent cardiometabolic health are warranted. This community-based longitudinal study evaluated the latent clustering structure and its stability for MetS during adolescence and investigated the relationship between changes in metabolic risk factors and transformation of MetS over 2 years of follow-up.

\section{Methods}




\section{Participants}

The adiposity-cardiovascular disease axis (adi-Cars) investigation was a large representative cohort study conducted to investigate multilevel determinants and risk profiles of cardiometabolic disease, prediabetes, and hyperuricemia among adolescents aged 12-14 years from southern Taiwan. The adolescents lived in three regions with varying levels of urbanization: Kaohsiung City, Pingtung County, and Taitung County. At the baseline survey, a three-stage procedure of random sampling of geographically stratified clusters was introduced to recruit the study participants. In stage one, Kaohsiung City, Pingtung County, and Taitung County were geographically stratified into nine, six, and four divisions, respectively. In stage two, all junior high schools within each division were compiled and listed, and 31 schools were randomly selected through computer-generated random numbers. In stage three, three classes (20-25 students per class) were randomly selected from each chosen school. One class was considered a cluster, and all students in the chosen classes were invited to participate in this study.

Baseline data were collected between September 2014 and June 2018 and follow-up data were measured between September 2017 and June 2021 . A total of 2,046 adolescents agreed to participate in the baseline anthropometric and questionnaire surveys (response rate: $94.9 \%$ ). Of them, 1,516 adolescents (74.1\%) participated in clinical biochemical examinations. In May 2021, a Covid-19 outbreak occurred in Taiwan and prevented follow-up by participants from three schools (these participants will be revisited after the outbreak). We excluded the students in these three schools in data analyses. Eventually, 1,246 adolescents from 28 schools with complete anthropometric and clinical blood data were followed. Of them, 1,155 participated in the anthropometric and questionnaire survey at follow-up (retention rate: $92.7 \%$; mean length of follow-up: 2.2 years), but only 896 participated in clinical blood examinations. This study adhered to the principles expressed in the Declaration of Helsinki. The Institutional Review Board of Kaohsiung Medical University Hospital reviewed and approved this research project. Written assents from the adolescents and consents from their parents/guardians were collected for both the baseline and follow-up surveys.

\section{Demographic and metabolic risk factors}

Multilevel-structured questionnaires were developed to obtain information on sociodemographic factors and lifestyle behaviors from adolescent participants and their parents. The urbanization of the township where each school is located was categorized into seven levels according to a socioeconomic cluster analysis of 359 Taiwan townships, with level 1 denoting the most urbanized [15]. Anthropometric parameters, including height, weight, hip circumference, waist circumference (WC), systolic BP (SBP), and diastolic BP (DBP), were measured at baseline and follow-up by a research team trained according to the World Health Organization guide to physical measurements [16]. Details of anthropometric measurements have been described previously [10, 17, 18]. Body mass index (BMI) was calculated as weight divided by height squared $\left(\mathrm{kg} / \mathrm{m}^{2}\right)$. Moreover, venous blood samples were obtained in school health centers in the morning after a >10-h overnight fast. Triglycerides (TG) and HDL-C concentrations were enzymatically determined using a chemistry autoanalyzer and commercially available reagents, and FPG levels were assessed using a glucose oxidase method (TBA-c16000, Toshiba, Tokyo, Japan) [19]. High-performance liquid chromatography (Bio-Rad Variant Turbo II HbA1c analyzer, Hercules, CA, USA) was used to measure glycosylated hemoglobin (HbA1c) values.

\section{MetS diagnosis}

MetS and MetS abnormal components were diagnosed using the IDF criteria for adolescents aged 10-18 years, TPA criteria for adolescents aged 8-18 years, and the Joint Interim Statement for adult MetS (JIS-Ad) $[6,20,21]$. Abdominal obesity is defined as WC $\geq 90$ percentile (or adult cutoff if lower) by the IDF, as $\mathrm{BMI}>95$ th percentile of age-sex-specific groups by the TPA, and as WC $\geq 90 \mathrm{~cm}$ in boys and WC $\geq 80 \mathrm{~cm}$ in girls by the JIS-Ad. Low HDL-C is defined as HDL-C $<40 \mathrm{mg} / \mathrm{dL}$ for adolescents aged 10-15 years and HDL-C $<40 \mathrm{mg} / \mathrm{dL}$ in adolescent boys and $<50 \mathrm{mg} / \mathrm{dL}$ in adolescent girls aged $16-18$ years by the IDF; however, the TPA and JIS-Ad define low HDL-C as HDL-C $<40 \mathrm{mg} / \mathrm{dL}$ in boys and $<50 \mathrm{mg} / \mathrm{dL}$ in girls. The IDF, TPA, and JIS-Ad have the same criteria for increased TG ( $\geq 150 \mathrm{mg} / \mathrm{dL}$ ), high FPG ( $\geq 100 \mathrm{mg} / \mathrm{dL}$ or previously diagnosed T2DM), and elevated BP (SBP $\geq 130 \mathrm{mmHg}, \mathrm{DBP} \geq 85 \mathrm{mmHg}$, or antihypertensive drug treatment). Supplementary Table S1 presents the complete definitions for the five abnormal components given by the IDF, TPA, and JISAd. Because the IDF and TPA have similar definitions for MetS abnormal components, we combined them as IDF-TPA criteria to accommodate any outlier definitions of the IDF and TPA and include all potential abnormal components. IDF-, TPA-, and IDF-TPA-defined MetS were the presence of abdominal obesity and any two other abnormal components, and JIS-Ad-defined MetS was the presence of any three abnormal components.

\section{Transformation of MetS status}

The IDF-TPA criteria for MetS and its abnormal components were used to investigate the transformation of MetS status over 2 years of follow-up in the adiCars cohort. Adolescents who were MetS-negative at both baseline and follow-up were defined as the never MetS group. Those who were MetS-negative at baseline but MetS-positive at follow-up were defined as the incident MetS group. Those who were MetS-positive at baseline and MetS-negative at follow-up were defined as the remitted MetS group. Those who were MetS-positive at both baseline and follow-up were defined as the persistent MetS group. The four groups were used as the main outcome of this investigation.

\section{Statistical analysis}

We applied 6 statistical procedures for data analysis. First, the demographic and metabolic risk factors measured are presented as mean \pm standard deviation for continuous variables and percentages for categorical variables. Second, exploratory factor analysis (EFA) was employed to investigate the latent factor clustering structure across metabolic parameters for baseline and follow-up surveys, similar to a prior study [8]. Before performing EFA, all variables were assessed for Gaussian normality, and nonnormally distributed variables were converted using the logarithm function. Next, we performed Bartlett's test of sphericity to examine whether metabolic risk factors have a significant correlation structure. The Kaiser-Meyer-Olkin (KMO) measure of sampling adequacy was used to evaluate the suitability of study data for structure detection. A KMO value of $>0.50$ was considered appropriate for factor analysis. In EFA, we used principal component analysis as the factor extraction approach and applied the eigenvalue $>1$ rule and surpassing the break in scree plots to extract factors $[22,23]$. Varimax rotation was applied to obtain more interpretable factor loadings, and the parameters with loadings $>0.4$ were used in interpreting factors. 
Third, Cohen's Kappa coefficient $(k)$ was calculated to evaluate the agreement of MetS (i.e., prevalence) defined by four MetS criteria between baseline and follow-up surveys [24]. The $k$ values of $0.21-0.40,0.41-0.60,0.61-0.80$, and $0.81-1.00$ were interpreted as fair, moderate, substantial, and almost perfect agreement, respectively [25]. Fourth, stratified by the typological group of MetS transformation, we applied a mixed model for repeated measures to assess within-person changes in the levels of metabolic risk factors measured at baseline and follow-up. For each participant, change in status between baseline and follow-up surveys (no change, turning negative, or turning positive) for each MetS component was also appraised. Fifth, because quaternary outcomes (i.e., never, incident, remitted, and persistent MetS) were investigated, we used a multinomial logistic regression model to assess the association of changes in metabolic risk factors with changes in MetS status over 2 years of follow-up. This modeling technique enables the simultaneous comparison of an outcome variable with $>2$ categories and has been verified to have a higher precision and statistical power compared with simple binary outcome analysis [26, 27]. Finally, incidence density was used to assess the status of new-onset MetS components in follow-up survey. Multivariable Cox proportional hazards models and adjusted hazard ratios (aHRs) were applied to evaluate the association between initial risk status and subsequent risk occurrence for each MetS component. All multivariable models were adjusted for sex, age, urbanization level, and metabolic risk factors, as appropriate.

\section{Results}

Table 1 presents the distributions of demographic and metabolic risk factors measured at baseline and follow-up for the adolescent cohort. The distributions of sex and urbanization level for the participants were similar between the two time-points; age was obviously increased by 2 years. Compared with baseline, the adolescents had higher SBP, DBP, and weight-related variables and lower HDL-C and FPG at follow-up.

Table 1

Demographic and metabolic risk factors of the adolescent cohort measured at the baseline and follow-up.

\begin{tabular}{|c|c|c|c|}
\hline & Baseline & Follow-up & \\
\hline Factors & $(\mathrm{N}=1246)$ & $(\mathrm{N}=1155)$ & $P$ value ${ }^{a}$ \\
\hline Age, Mean \pm SD & $12.6 \pm 0.7$ & $14.6 \pm 0.7$ & $<0.001$ \\
\hline \multicolumn{4}{|l|}{ Sex, \% } \\
\hline Boy & 49.0 & 49.1 & 0.979 \\
\hline Girl & 51.0 & 50.9 & \\
\hline \multicolumn{4}{|l|}{ Urbanization level, \% } \\
\hline Level 1-2 & 49.9 & 49.3 & 0.946 \\
\hline Level 3-4 & 28.3 & 28.7 & \\
\hline Level 5-7 & 21.8 & 22.0 & \\
\hline \multicolumn{4}{|l|}{ Metabolic risk factors, Mean \pm SD } \\
\hline \multicolumn{4}{|l|}{ Anthropometric parameters } \\
\hline Systolic blood pressure, $\mathrm{mmHg}$ & $111.8 \pm 13.1$ & $114.1 \pm 14.0$ & $<0.001$ \\
\hline Diastolic blood pressure, $\mathrm{mmHg}$ & $64.0 \pm 9.2$ & $65.3 \pm 9.0$ & 0.001 \\
\hline Waist circumference, $\mathrm{cm}$ & $71.6 \pm 11.4$ & $74.9 \pm 11.9$ & $<0.001$ \\
\hline Hip circumference, $\mathrm{cm}$ & $87.6 \pm 9.8$ & $93.5 \pm 9.4$ & $<0.001$ \\
\hline Body mass index, $\mathrm{Kg} / \mathrm{m}^{2}$ & $20.7 \pm 4.5$ & $21.9 \pm 4.8$ & $<0.001$ \\
\hline \multicolumn{4}{|l|}{ Clinical parameters $^{b}$} \\
\hline HDL-cholesterol, mg/dL & $54.1 \pm 11.2$ & $50.3 \pm 10.9$ & $<0.001$ \\
\hline Triglyceride, mg/dL & $78.1 \pm 39.2$ & $76.7 \pm 36.1$ & 0.408 \\
\hline Fasting plasma glucose, mg/dL & $89.8 \pm 11.0$ & $88.2 \pm 16.2$ & 0.006 \\
\hline Glycated hemoglobin, \% & $5.3 \pm 0.4$ & $5.3 \pm 0.6$ & 0.650 \\
\hline \multicolumn{4}{|c|}{$\begin{array}{l}\text { Abbreviation: } \mathrm{HDL}-\mathrm{C} \text {, high-density lipoprotein cholesterol. } \\
\text { a } P \text { value for the difference in study parameters between baseline and follow-up. } \\
{ }^{\text {b} B l o o d ~ p a r a m e t e r s ~ w e r e ~ m e a s u r e d ~ f o r ~} 896 \text { adolescents at follow-up. }\end{array}$} \\
\hline
\end{tabular}

Study data on nine metabolic risk factors collected at both baseline and follow-up had a significant correlation structure (Table 2, $P$ for Bartlett's test $<0.001$ ) and qualified for factor analysis (KMO, 0.782 and 0.794 , both $>0.5)$. EFA extracted three clustering factors from the study variables measured at both timepoints (all factors, eigenvalues $>1$ and surpassing the break in scree plots; Fig. S1). The factor structures were similar at baseline and follow-up; both comprised a fat factor (BMI, WC, hip circumference, HDL-C, and TG), a BP factor (SBP and DBP), and a glucose factor (FPG and HbA1c). Factor loadings for 
each factor and the proportion of variance explained by the three factors ( $68.8 \%$ and $69.7 \%$, respectively) were very comparable between the data for the two time-points. All metabolic risk factors used to interpret each factor structure had a factor loading of $\geq 0.508$.

Table 2

Exploratory factor analysis-derived factors, factor loadings, and proportions of variance explained for metabolic risk factors measured at baseline and follow-up in adolescents.

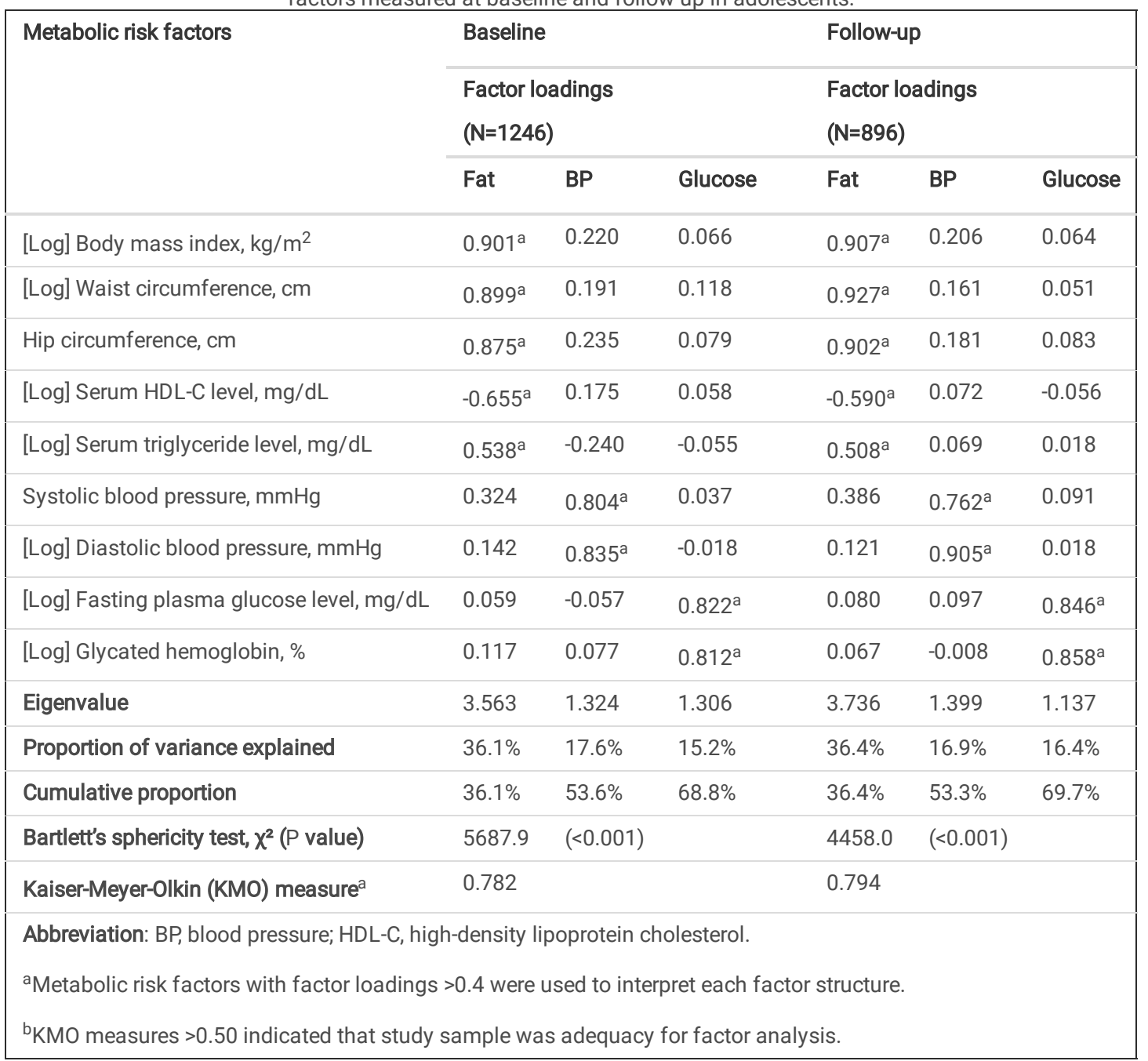

Table 3 displays the criterion-specific prevalence and transformations of adolescent MetS defined by four criteria over 2 years of follow-up. The prevalence of MetS was $2.8 \%-6.0 \%$ at baseline and $4.5 \%-6.5 \%$ at follow-up, with a 'fair level' of agreement $(k, 0.313-0.367)$, indicating that MetS status changes with time (in this case, 2 years) in adolescents. Among adolescents who were MetS-negative at baseline, $3.2 \%-4.4 \%$ had incident MetS after 2 years. Among adolescents who were MetS-positive at baseline, 52.0\%-61.9\% experienced MetS remission and 38.1\%-48.0\% experienced MetS persistence. 
Table 3

Baseline and follow-up prevalences and transformations of metabolic syndrome in adolescents over 2 years of follow-up.

\begin{tabular}{|c|c|c|c|c|c|c|c|c|c|c|c|}
\hline \multirow[t]{2}{*}{ MetS criteria } & \multicolumn{2}{|c|}{$\begin{array}{l}\text { Prevalence } \\
\text { at baseline }\end{array}$} & \multicolumn{2}{|c|}{$\begin{array}{l}\text { Incident } \\
\text { MetS }\end{array}$} & \multicolumn{2}{|c|}{$\begin{array}{l}\text { Remitted } \\
\text { MetS }\end{array}$} & \multicolumn{2}{|c|}{$\begin{array}{l}\text { Persistent } \\
\text { MetS }\end{array}$} & \multicolumn{2}{|c|}{$\begin{array}{l}\text { Prevalence } \\
\text { at follow-up }\end{array}$} & \multirow{2}{*}{$\begin{array}{l}\text { MetS } \\
\text { Kappa } \\
(P \text { value })^{a}\end{array}$} \\
\hline & No. & $\begin{array}{l}\% \\
(95 \% \mathrm{Cl})\end{array}$ & No. & $\begin{array}{l}\% \\
(95 \% \mathrm{Cl})\end{array}$ & No. & $\begin{array}{l}\% \\
(95 \% \mathrm{Cl})\end{array}$ & No. & $\begin{array}{l}\% \\
(95 \% \mathrm{Cl})\end{array}$ & No. & $\begin{array}{l}\% \\
(95 \% \mathrm{Cl})\end{array}$ & \\
\hline \multicolumn{12}{|l|}{ IDF } \\
\hline Yes & 25 & 2.8 & 28 & 3.2 & 13 & 52.0 & 12 & 48.0 & 40 & 4.5 & 0.347 \\
\hline No & 871 & $(1.9-4.1)$ & 843 & $(2.2-4.6)$ & 12 & (32.2-71.2) & 13 & (28.8-67.8) & 856 & $(3.3-6.0)$ & $(<0.001)$ \\
\hline \multicolumn{12}{|l|}{ TPA } \\
\hline Yes & 52 & 5.8 & 31 & 3.7 & 31 & 59.6 & 21 & 40.4 & 52 & 5.8 & 0.367 \\
\hline No & 844 & $(4.4-7.5)$ & 813 & $(2.6-5.2)$ & 21 & $(45.6-72.2)$ & 31 & $(27.8-54.4)$ & 844 & $(4.4-7.5)$ & $(<0.001)$ \\
\hline \multicolumn{12}{|l|}{ JIS-Adult } \\
\hline Yes & 42 & 4.7 & 34 & 4.0 & 26 & 61.9 & 16 & 38.1 & 50 & 5.6 & 0.313 \\
\hline No & 854 & $(3.5-6.3)$ & 820 & $(2.9-5.5)$ & 16 & $(46.1-75.5)$ & 26 & $(24.5-53.9)$ & 846 & $(4.3-7.3)$ & $(<0.001)$ \\
\hline \multicolumn{12}{|l|}{ IDF-TPA } \\
\hline Yes & 54 & 6.0 & 37 & 4.4 & 33 & 61.1 & 21 & 38.9 & 58 & 6.5 & 0.333 \\
\hline No & 842 & $(4.6-7.8)$ & 805 & $(3.2-6.0)$ & 21 & (47.3-73.3) & 33 & $(26.7-52.7)$ & 838 & $(5.0-8.3)$ & $(<0.001)$ \\
\hline
\end{tabular}

Table 4 presents within-person changes in metabolic risk factors between baseline and follow-up, stratified by MetS typology per the IDF-TPA criteria. In the never group, BMI, WC, SBP, and DBP at follow-up were higher and HDL-C and FPG were lower than the corresponding values at baseline. In the incident group, the within-person changes in BMI, WC, SBP, DBP, and HDL-C were significant and greater than those in the never group. In the remission group, TG and FPG levels were noticeably reduced at follow-up. In the persistent group, the values of metabolic risk factors were relatively high at baseline, and SBP also increased at the 2-year follow-up.

Table 4

Distributions and changes of metabolic risk factors between baseline and follow-up for never, incident, remitted, and persistent metabolic sy

\begin{tabular}{|c|c|c|c|c|c|c|c|c|c|c|c|c|}
\hline \multirow[b]{2}{*}{ Factors } & \multicolumn{4}{|c|}{ Never $(\mathrm{N}=805)$} & \multicolumn{4}{|c|}{ Incident $(\mathrm{N}=37)$} & \multicolumn{4}{|c|}{ Remitted (N=33) } \\
\hline & $\begin{array}{l}\text { Baseline } \\
\text { Mean }\end{array}$ & $\begin{array}{l}\text { Follow- } \\
\text { up } \\
\text { Mean }\end{array}$ & $\begin{array}{l}\text { WP } \\
\text { Change }^{b}\end{array}$ & $\mathrm{P}^{\mathrm{c}}$ & $\begin{array}{l}\text { Baseline } \\
\text { Mean }\end{array}$ & $\begin{array}{l}\text { Follow- } \\
\text { up } \\
\text { Mean }\end{array}$ & $\begin{array}{l}\text { WP } \\
\text { Change }^{b}\end{array}$ & $\mathrm{P}^{\mathrm{c}}$ & $\begin{array}{l}\text { Baseline } \\
\text { Mean }\end{array}$ & $\begin{array}{l}\text { Follow- } \\
\text { up } \\
\text { Mean }\end{array}$ & $\begin{array}{l}\text { WP } \\
\text { Change }^{b}\end{array}$ & $\mathrm{P}^{\mathrm{c}}$ \\
\hline BMI & 19.93 & 21.09 & $1.16^{\star}$ & $<0.001$ & 26.76 & 28.59 & $1.83^{\star}$ & $<0.001$ & 27.21 & 28.12 & 0.91 & 0.075 \\
\hline WC & 69.90 & 72.96 & $3.06^{\star}$ & $<0.001$ & 85.51 & 91.06 & $5.55^{\star}$ & $<0.001$ & 87.43 & 90.06 & 2.63 & 0.094 \\
\hline SBP & 111.04 & 111.97 & $0.94 *$ & 0.049 & 119.38 & 132.57 & $13.19 *$ & $<0.001$ & 121.85 & 122.06 & 0.21 & 0.932 \\
\hline DBP & 63.68 & 64.43 & $0.75^{\star}$ & 0.049 & 67.24 & 72.62 & $5.38^{*}$ & 0.001 & 70.97 & 69.06 & -1.91 & 0.333 \\
\hline HDL-C & 55.00 & 51.33 & $-3.67 *$ & $<0.001$ & 47.03 & 41.08 & $-5.95^{\star}$ & $<0.001$ & 42.43 & 43.04 & 0.61 & 0.581 \\
\hline TG & 73.38 & 73.03 & -0.35 & 0.763 & 99.78 & 109.22 & 9.43 & 0.236 & 123.39 & 95.27 & $-28.12^{\star}$ & $<0.001$ \\
\hline FPG & 89.48 & 87.20 & $-2.29 *$ & $<0.001$ & 89.68 & 89.43 & -0.24 & 0.872 & 95.97 & 87.03 & $-8.94^{\star}$ & $<0.001$ \\
\hline HbA1c & 5.29 & 5.28 & -0.004 & 0.672 & 5.31 & 5.28 & -0.03 & 0.603 & 5.30 & 5.31 & 0.02 & 0.776 \\
\hline
\end{tabular}

Abbreviations: WP, within-person; BMI, body mass index; WC, waist circumference; HDL-C, high-density lipoprotein cholesterol; TG, triglyceride; SBP, systolic bl pressure; FPG, fasting plasma glucose; HbA1c, glycated hemoglobin.

aIDF-TPA criteria were used to determine adolescent metabolic syndrome.

${ }^{\text {b}}$ The mean level for within-person change in the metabolic risk factors between baseline and follow-up. Here, * denoting $P<0.05$ for the pair difference betwe ${ }^{\mathrm{c}} P$ value for WP change was obtained from the mixed model for repeated measures adjusted for sex, age, and urbanization level. 
Table 5 displays the association of changes in metabolic risk factors with changes in MetS status at follow-up. After adjustment for covariates, adolescents with a $1 \mathrm{mmHg}$ increase in $\triangle \mathrm{SBP}$ had a 1.07-fold risk of incident MetS at follow-up. Compared with the never group, the remission group had a greater elevation in HDL-C ( $\triangle \mathrm{HDL}-\mathrm{C}, 0.61 \mathrm{vs}-3.67 \mathrm{mg} / \mathrm{dL})$ and a greater decrease in TG and FPG $(\Delta \mathrm{TG},-28.12 \mathrm{vs}-0.35 \mathrm{mg} / \mathrm{dL}$ and $\Delta \mathrm{FPG},-8.94 \mathrm{vs}-2.29 \mathrm{mg} / \mathrm{dL})$. Compared with those with persistent MetS, participants having a 1 unit increase in $\triangle$ SBP, $\triangle T$ G, and $\Delta F P G$ had a 0.95 , 0.98, and 0.94-fold, respectively, lower likelihood of MetS remission after 2 years.

Table 5

Adjusted associations of the changes in metabolic risk factors over 2 years of follow-up with incident, remitted, and persistent metabolic syndromea in

\begin{tabular}{|c|c|c|c|c|c|c|c|c|c|}
\hline \multirow{3}{*}{$\begin{array}{l}\text { Within person } \\
\text { change }^{b}\end{array}$} & & & & & & & & & \\
\hline & \multicolumn{2}{|c|}{ Never $(\mathrm{N}=805)$} & \multicolumn{2}{|c|}{ Incident (N=37) } & \multicolumn{2}{|c|}{ Remitted (N=33) } & \multicolumn{2}{|c|}{ Persistent $(\mathrm{N}=21)$} & \multirow{2}{*}{ 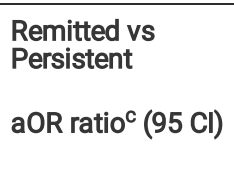 } \\
\hline & $\begin{array}{l}\text { Mean } \\
(\mathrm{SD})\end{array}$ & $\begin{array}{l}\text { aOR } \\
\text { (Ref.) }\end{array}$ & $\begin{array}{l}\text { Mean } \\
\text { (SD) }\end{array}$ & $\begin{array}{l}\mathrm{aOR}^{\mathrm{c}} \\
(95 \mathrm{Cl})\end{array}$ & $\begin{array}{l}\text { Mean } \\
\text { (SD) }\end{array}$ & $\begin{array}{l}\mathrm{aOR}^{\mathrm{c}} \\
(95 \mathrm{Cl})\end{array}$ & $\begin{array}{l}\text { Mean } \\
(\mathrm{SD})\end{array}$ & $\begin{array}{l}\text { aOR } \\
(95 \mathrm{Cl})\end{array}$ & \\
\hline \multirow[t]{2}{*}{$\Delta \mathrm{BMI}, \mathrm{Kg} / \mathrm{m}^{2}$} & 1.16 & 1.0 & 1.83 & 0.98 & 0.91 & 1.08 & 1.12 & 1.09 & 0.99 \\
\hline & $(1.71)$ & & $(1.90)$ & $(0.77-1.25)$ & $(2.98)$ & $\begin{array}{l}(0.81- \\
1.43)\end{array}$ & $(3.31)$ & $\begin{array}{l}(0.78- \\
1.52)\end{array}$ & $(0.64-1.52)$ \\
\hline \multirow[t]{2}{*}{$\Delta \mathrm{WC}, \mathrm{cm}$} & 3.06 & 1.0 & 5.55 & 1.05 & 2.63 & 0.99 & 3.16 & 1.02 & 0.97 \\
\hline & $(6.11)$ & & $(6.67)$ & $(0.97-1.12)$ & $(9.15)$ & $\begin{array}{l}(0.91- \\
1.07)\end{array}$ & $(9.03)$ & $\begin{array}{l}(0.92- \\
1.12)\end{array}$ & $(0.86-1.10)$ \\
\hline \multirow[t]{2}{*}{$\Delta S B P, m m H g$} & 0.94 & 1.0 & 13.19 & $1.07 \star$ & 0.21 & 1.01 & 10.86 & $1.07^{\star}$ & $0.95^{\star}$ \\
\hline & (13.47) & & (13.65) & $(1.04-1.11)$ & (14.54) & $\begin{array}{l}(0.97- \\
1.04)\end{array}$ & (18.09) & $\begin{array}{l}(1.02- \\
1.11)\end{array}$ & $(0.90-0.99)$ \\
\hline \multirow[t]{2}{*}{$\Delta \mathrm{DBP}, \mathrm{mmHg}$} & 0.75 & 1.0 & 5.38 & 0.99 & -1.91 & 0.97 & 4.72 & 0.99 & 0.98 \\
\hline & $(10.80)$ & & $(9.16)$ & $(0.96-1.03)$ & $(11.50)$ & $\begin{array}{l}(0.94- \\
1.01)\end{array}$ & $(14.98)$ & $\begin{array}{l}(0.95- \\
1.04)\end{array}$ & $(0.93-1.04)$ \\
\hline \multirow[t]{2}{*}{$\Delta \mathrm{HDL}-\mathrm{C}, \mathrm{mg} / \mathrm{dL}$} & -3.67 & 1.0 & -5.95 & 0.97 & 0.61 & $1.08^{\star}$ & -2.16 & 1.03 & 1.05 \\
\hline & $(7.86)$ & & $(6.45)$ & $(0.93-1.02)$ & $(6.43)$ & $\begin{array}{l}(1.03- \\
1.14)\end{array}$ & $(6.41)$ & $\begin{array}{l}(0.97- \\
1.10)\end{array}$ & $(0.97-1.14)$ \\
\hline \multirow[t]{2}{*}{$\Delta \mathrm{TG}, \mathrm{mg} / \mathrm{dL}$} & -0.35 & 1.0 & 9.43 & 1.01 & -28.12 & $0.98^{*}$ & 2.71 & 0.99 & $0.98^{*}$ \\
\hline & (33.12) & & (49.13) & $\begin{array}{l}(0.997- \\
1.02)\end{array}$ & $(41.89)$ & $\begin{array}{l}(0.97- \\
0.99)\end{array}$ & $(52.18)$ & $\begin{array}{l}(0.98- \\
1.01)\end{array}$ & $(0.97-0.99)$ \\
\hline \multirow[t]{2}{*}{$\Delta \mathrm{FPG}, \mathrm{mg} / \mathrm{dL}$} & -2.29 & 1.0 & -0.24 & 1.02 & -8.94 & $0.96^{*}$ & 22.05 & 1.02 & $0.94 *$ \\
\hline & (10.39) & & $(9.33)$ & $(0.99-1.05)$ & $(10.80)$ & $\begin{array}{l}(0.93- \\
0.99)\end{array}$ & $(65.38)$ & $\begin{array}{l}(0.99- \\
1.06)\end{array}$ & $(0.89-0.98)$ \\
\hline \multirow[t]{2}{*}{$\Delta \mathrm{HbA} 1 \mathrm{c}, \%$} & -0.004 & 1.0 & -0.03 & 0.98 & 0.02 & 0.77 & 0.67 & 2.21 & 0.35 \\
\hline & $(0.29)$ & & $(0.32)$ & $(0.33-2.93)$ & $(0.31)$ & $\begin{array}{l}(0.20- \\
2.96)\end{array}$ & $(1.97)$ & $\begin{array}{l}(0.70- \\
6.99)\end{array}$ & $(0.06-2.01)$ \\
\hline \multicolumn{10}{|c|}{$\begin{array}{l}\text { Abbreviations: SD, standard deviation; Ref., reference group; aOR, adjusted } \\
\text { lipoprotein cholesterol; TG, triglyceride; SBP, systolic blood pressure; DBP, dia } \\
\text { hemoglobin; *, } P<0.05 \text {. }\end{array}$} \\
\hline
\end{tabular}

Table 6 summarizes the effects of the change of risk condition between baseline and follow-up for five MetS components on incident, remitted, and persistent MetS. After adjustment for the effects of other MetS components and covariates, change in the status of each MetS component to positive at follow-up contributed to a higher risk of incident MetS, with TG, BP, and FPG having a >29-fold risk (aOR, 29.1, 53.8, and 57.1, respectively). Conversely, change in the status of any MetS component to negative at follow-up influenced MetS remission, with HDL-C, FPG, and TG having >10-fold effects (aOR, 10.8, 14.2, and 97.6, respectively). Transformation of BP and TG to positive was linked to an elevated risk of persistent MetS (aOR, 11.6 and 7.8 , respectively). 
Table 6

Effects of the change of risk condition in five components of metabolic syndrome (MetS)a between baseline and follow-up on incident, remitted, and persistent MetS in adolescents.

\begin{tabular}{|c|c|c|c|c|c|c|c|c|c|c|}
\hline \multirow{2}{*}{$\begin{array}{l}\text { MetS } \\
\text { components/ } \\
\text { risk condition }\end{array}$} & $\begin{array}{l}\text { Never } \\
(\mathrm{N}=805)\end{array}$ & \multicolumn{3}{|l|}{$\begin{array}{l}\text { Incident } \\
(\mathrm{N}=37)\end{array}$} & \multicolumn{3}{|l|}{$\begin{array}{l}\text { Remitted } \\
(\mathrm{N}=33)\end{array}$} & \multicolumn{3}{|l|}{$\begin{array}{l}\text { Persistent } \\
(\mathrm{N}=21)\end{array}$} \\
\hline & No. $(\%)$ & No. $(\%)$ & $a O R^{b}$ & (95 Cl) & No. $\quad(\%)$ & $a O R^{b}$ & $(95 \mathrm{Cl})$ & No. $\quad(\%)$ & $a O R^{b}$ & $\begin{array}{l}(95 \\
\mathrm{Cl})\end{array}$ \\
\hline
\end{tabular}

\begin{tabular}{|c|c|c|c|c|c|c|c|c|c|c|c|c|c|c|}
\hline \multicolumn{15}{|l|}{$\begin{array}{l}\text { Abdominal } \\
\text { obesity }\end{array}$} \\
\hline No change & 717 & $(89.1)$ & 31 & $(83.8)$ & 1.0 & & 27 & $(81.8)$ & 1.0 & & 21 & $(100.0)$ & 1.0 & \\
\hline Turn negative & 54 & $(6.7)$ & 0 & $(0.0)$ & na & & 6 & $(18.2)$ & 3.9 & $\begin{array}{l}(1.1- \\
14.2)\end{array}$ & 0 & $(0.0)$ & na & \\
\hline Turn positive & 34 & $(4.2)$ & 6 & $(16.2)$ & 4.5 & $\begin{array}{l}(1.0- \\
19.9)\end{array}$ & 0 & $(0.0)$ & na & & 0 & $(0.0)$ & na & \\
\hline \multicolumn{15}{|l|}{ Elevated BP } \\
\hline No change & 702 & $(87.2)$ & 18 & $(48.7)$ & 1.0 & & 26 & $(78.8)$ & 1.0 & & 10 & $(47.6)$ & 1.0 & \\
\hline Turn negative & 49 & $(6.1)$ & 0 & $(0.0)$ & na & & 7 & $(21.2)$ & 4.7 & $\begin{array}{l}(1.4- \\
15.8)\end{array}$ & 2 & $(9.5)$ & 3.6 & $\begin{array}{l}(0.7- \\
17.6)\end{array}$ \\
\hline Turn positive & 54 & $(6.7)$ & 19 & $(51.4)$ & 53.8 & $\begin{array}{l}(16.8- \\
171.9)\end{array}$ & 0 & $(0.0)$ & na & & 9 & $(42.9)$ & 11.6 & $\begin{array}{l}(3.9- \\
34.8)\end{array}$ \\
\hline \multicolumn{15}{|l|}{ Low HDL-C } \\
\hline No change & 651 & $(80.9)$ & 18 & $(48.7)$ & 1.0 & & 25 & (75.8) & 1.0 & & 16 & (76.2) & 1.0 & \\
\hline Turn negative & 34 & $(4.2)$ & 0 & $(0.0)$ & na & & 8 & $(24.2)$ & 10.8 & $\begin{array}{l}(3.0- \\
38.5)\end{array}$ & 1 & $(4.8)$ & 1.4 & $\begin{array}{l}(0.2- \\
12.9)\end{array}$ \\
\hline Turn positive & 120 & (14.9) & 19 & $(51.4)$ & 16.7 & $\begin{array}{l}(5.7- \\
48.5)\end{array}$ & 0 & $(0.0)$ & na & & 4 & (19.1) & 1.9 & $\begin{array}{l}(0.6- \\
6.4)\end{array}$ \\
\hline \multicolumn{15}{|l|}{ Increased TG } \\
\hline No change & 771 & (95.8) & 27 & (73.0) & 1.0 & & 19 & $(57.6)$ & 1.0 & & 16 & (76.2) & 1.0 & \\
\hline Turn negative & 17 & (2.1) & 1 & $(2.7)$ & 0.8 & $(0.1-8.2)$ & 14 & $(42.4)$ & 97.6 & $\begin{array}{l}(28.2- \\
338.0)\end{array}$ & 3 & (14.3) & 5.8 & $\begin{array}{l}(1.2- \\
28.4)\end{array}$ \\
\hline Turn positive & 17 & $(2.1)$ & 9 & $(24.3)$ & 29.1 & $\begin{array}{l}(6.5- \\
131.0)\end{array}$ & 0 & $(0.0)$ & na & & 2 & (9.5) & 7.8 & $\begin{array}{l}(1.5- \\
42.0)\end{array}$ \\
\hline \multicolumn{15}{|l|}{ High FPG } \\
\hline No change & 701 & $(87.1)$ & 25 & $(67.6)$ & 1.0 & & 18 & $(54.6)$ & 1.0 & & 14 & $(66.7)$ & 1.0 & \\
\hline Turn negative & 75 & (9.3) & 2 & (5.4) & 0.4 & $(0.1-2.2)$ & 14 & $(42.4)$ & 14.2 & $\begin{array}{l}(4.8- \\
42.4)\end{array}$ & 6 & $(28.6)$ & 2.6 & $\begin{array}{l}(0.8- \\
8.2)\end{array}$ \\
\hline Turn positive & 29 & $(3.6)$ & 10 & $(27.0)$ & 57.1 & $\begin{array}{l}(15.2- \\
215.1)\end{array}$ & 1 & (3.0) & 0.7 & $\begin{array}{l}(0.04- \\
13.3)\end{array}$ & 1 & $(4.8)$ & 3.4 & $\begin{array}{l}(0.4- \\
29.5)\end{array}$ \\
\hline \multicolumn{15}{|c|}{$\begin{array}{l}\text { Abbreviations: aOR, adjusted odds ratio; WC, waist circumference; HDL-C, high-density lipoprotein cholesterol; TG, triglyceride; BP, blood pressure; FPG, } \\
\text { fasting plasma glucose; na, non-appreciable due to no subject in that group. }\end{array}$} \\
\hline
\end{tabular}

Table 7 displays the baseline prevalence, follow-up incidence density, and aHR of MetS abnormal components associated with their original status. The baseline prevalence was $24.9 \%, 10.6 \%, 21.1 \%, 5.5 \%$, and $11.4 \%$ for abdominal obesity, elevated BP, low HDL-C, increased TG, and high FPG, respectively. Among the five abnormal components, low HDL-C had the highest incidence density ( $9.6 \%$ per year) in adolescents with an initial normal status. Abdominal obesity and low HDL-C had a greater persistent incidence density (34.3\% and 36.5\% per year, respectively) in participants with an original positive status. Compared with a normal status at baseline in the five MetS components, an abnormal status at baseline was associated with a higher risk of the abnormal status persisting at follow-up, with abdominal obesity and increased TG rendering a >5.0-fold risk each (aHR, 15.0 and 5.7, respectively). 
Table 7

Baseline prevalences, follow-up incidence densities, and adjusted hazard ratios of abnormal components of metabolic syndrome associated with initial status over 2 years of follow-up in adolescents.

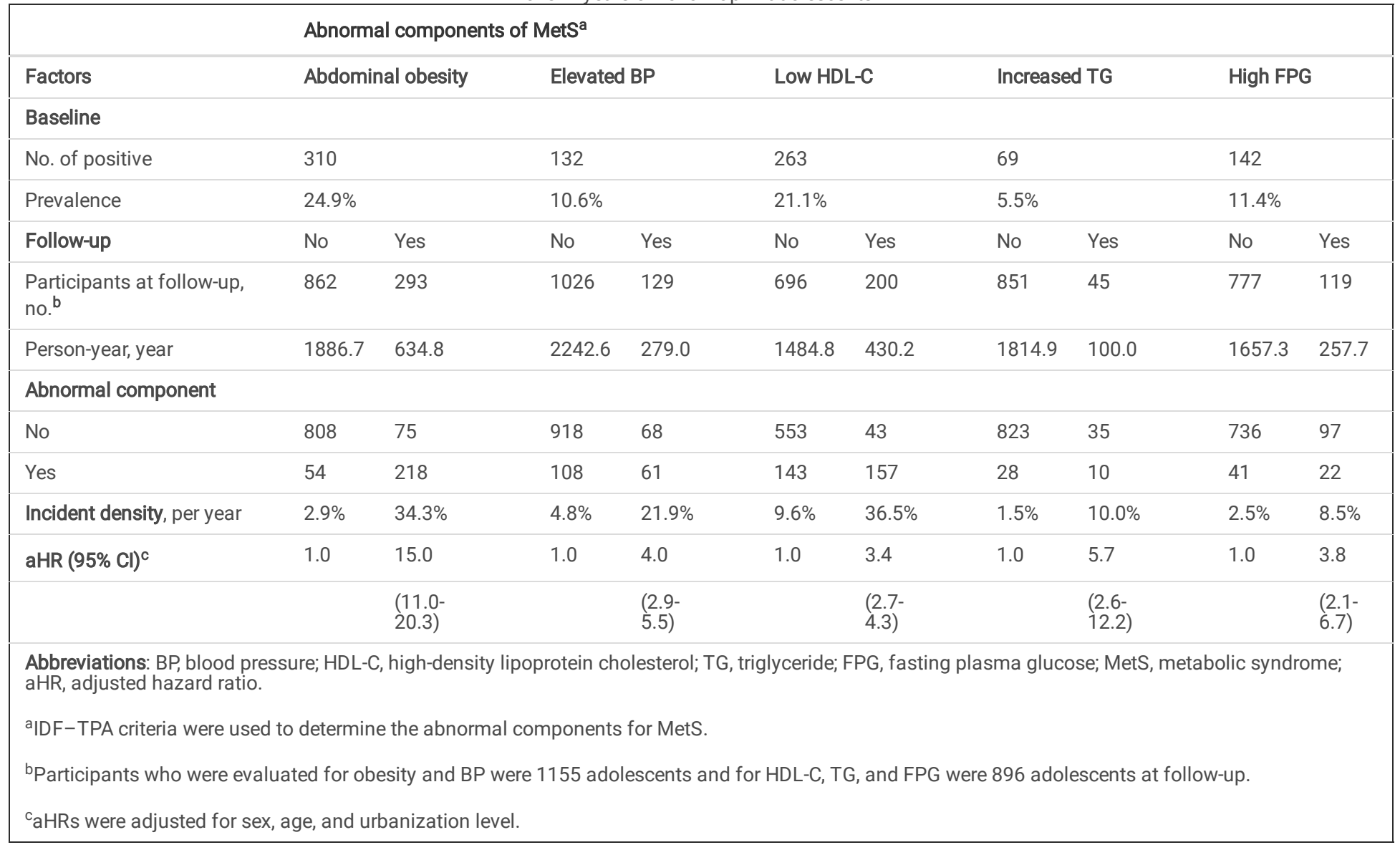

\section{Discussion}

This study presents findings that demonstrate that the structure of parameter clustering for adolescent MetS at baseline and follow-up were comparable. Elevated SBP was associated with MetS incidence and persistence, and decreased SBP, TG, and FPG were associated with MetS remission after 2 years. Adolescents who had an abnormal MetS component at baseline were more likely to have the component be abnormal at follow-up than those who were normal for each MetS component.

MetS reflects a clustering of metabolic risk parameters, which are believed to originate from the common pathophysiological mechanisms of insulin resistance [28]. In this study, a fat-BP-glucose three-factor structure for MetS was observed both in adolescents aged 12-14 years (baseline survey) and 15-17 years (follow-up survey), with analogous factor loadings and proportions of total variance explained (68.8\% vs $69.7 \%$ ). In one school-based longitudinal investigation of adolescents aged 12-19 years, the overall parameter clustering structure of metabolic risks was identified to be no change after 3-years of follow-up [8]. These findings strengthen the argument that the mechanistic underpinning for MetS is stable during adolescence. Alternatively, the verification of a multifactor structure highlights the necessity of evaluating multisystem dysregulation in MetS using factor analysis. A risk score for MetS derived from confirmatory factor analysis has been applied to measure the effect of the spectrum of MetS severity on T2DM and cardiometabolic disease [29-31].

Using four criteria to diagnose MetS in adolescents, we identified that 3.2\%-4.4\% of adolescents in the adi-Cars cohort had incident MetS and $52.0 \%-61.9 \%$ of those with MetS experienced remission. Consistent with our findings, one longitudinal study that employed three MetS definitions for adolescents revealed an incident MetS rate of $3.8 \%-5.2 \%$ and MetS remission rate of $48.6 \%-56.1 \%$ after 2.7 years [8]. Although the four criteria for MetS abnormal components had different cutoff values, the agreement of MetS diagnosis between baseline and follow-up was similar across these criteria ( $k$, $0.313-0.367)$; this illustrates the stability of longitudinal transformation pattern in MetS status during adolescent development. Recent prospective investigations have indicated that incident MetS and persistent MetS assessed by 2 time-points surveys can substantially predict the risk of subclinical atherosclerosis and T2DM in adult life $[32,33]$. Determining transformations in MetS status over time is thus a promising approach for estimating its influence on cardiometabolic disorders.

Our data revealed that intraindividual changes between baseline and follow-up in weight- and BP-related variables, HDL-C, and FPG were significant in the never MetS group, thus demonstrating the variability of metabolic risk parameters in childhood development. After adjustment for all covariates, a high SBP increase ( $\triangle \mathrm{SBP}$ ) was associated with a high risk of new-onset MetS (aOR, 1.07 for $1 \mathrm{mmHg}$ increase, Table 5), implying that SBP elevation is critical for MetS occurrence in this population. Compared with adolescents having persistent MetS, decreases in the SBP, TG, and FPG levels were associated with an increased likelihood of MetS remission (aOR, 1.05, 1.02, and 1.06, respectively, for 1 unit decrease, Table 5). Clinical studies have revealed that patients who received a short-term intensive drug treatment to lower blood glucose, BP, and cholesterol levels had a long-term reduction in the risk of T2DM and cardiovascular 
disorders, even after treatment cessation (known as the cardiometabolic memory phenomenon) [34]. Our findings underline the need for interventions among adolescents with MetS such as dietary improvement and exercise promotion with the aim to reducing SBP, TG, and FPG levels.

In this study, incident MetS at follow-up was associated with positivity in all five MetS components; in particular, FPG, BP, and TG turning positive each had a $>29$-fold risk. This risk pattern illustrates the strength between MetS incidence and the transformation of risk status for each component, and it indicates the most critical targets-FPG, BP, and TG-for the prevention of MetS occurrence. By contrast, MetS remission 2 years later was associated with a change in the status of the five components to negative, with TG and FPG turning negative being related to a >14-fold likelihood of remission (remission group: TG and FPG, both $42.2 \%$ turning normal; never group: $2.1 \%$ and $9.3 \%$, respectively). The status change in TG and FPG can be considered an examined focus for syndrome remission among adolescents with MetS. Most adolescents in the persistent typology maintained their original status (47.6\%-100.0\%), with only a low proportion exhibiting a negative transformation on the five MetS components $(0.0 \%-28.6 \%)$.

Surveillance and monitoring of the incidence and persistence of five MetS components are vital tasks in adolescent cardiometabolic health [2, 14]. In our cohort, among the five MetS components, low HDL-C had the highest incidence rate (9.6\% per year), whereas abdominal obesity and low LDL-C had the greatest persistence rate (34.3\% and $36.5 \%$ per year, respectively). These data indicate specific risk factors that need enhanced monitoring. A combined assessment involving two longitudinal investigations demonstrated that incident MetS and persistent MetS during the transition from adolescence to young adulthood are associated with a 1.7- and 3.4-fold risk, respectively, of high carotid artery intima-media thickness and a 4.4- and 12.2-fold of T2DM in adulthood [32]. Because the likelihood of persistence of each MetS component was higher than that for new onset (aHR, 3.4-15.0, Table 7), screening for existing abnormal MetS components can be more beneficial than preventing new-onset abnormal components.

This study had several strengths. First, a large-scale representative community-based cohort was used to prospectively assess the stability and typological transformation of adolescent MetS and their relation to the change of metabolic risk factors. Second, our investigative framework and methodology can be adopted to other countries that wish to evaluate their own typological transformations in MetS status and attendant influences on cardiometabolic disorders among adolescents and adults. Third, several criteria with specific cutoff points for MetS diagnosis were simultaneously used to determine the agreement and stability for changes in MetS status over 2 years.

This study also had a few limitations. First, adolescents from three schools could not be followed due to the COVID-19 outbreak in Taiwan, and their data were excluded from this evaluation. However, the distributions of sex, age, urbanization level, and weight variables were comparable between the participants in the excluded and remaining schools. Second, our cohort included only Taiwanese adolescents, and thus, our findings may not be generalizable to other adolescent populations.

\section{Conclusions}

This 2-year follow-up study revealed that the structure of metabolic parameter clustering for MetS is stable during adolescence. Changes in metabolic risk factors affect the transformation in MetS status of adolescents. Any positive MetS component in childhood has a high probability of persisting; accordingly, early identification of each abnormal component and attendant intervention are vital for reducing the future risk of cardiometabolic disorders.

\section{Abbreviations}

aHR: adjusted hazard ratios; adi-Cars: adiposity-cardiovascular-disease axis; BP: blood pressure; BMI: body mass index; DBP: diastolic blood pressure; EFA: exploratory factor analysis; HbA1c: glycated hemoglobin; HDL-C: high-density lipoprotein cholesterol;

HC: hip circumference; IDF-TPA: International Diabetes Federation and Taiwan Pediatric Association; JIS-Ad: Joint Interim Statement for adult MetS; KMO: Kaiser-Meyer-Olkin;

MetS: metabolic syndrome; FPG: fasting plasma glucose; SBP: systolic BP; T2DM: type 2 diabetes; TG: triglyceride; WC: waist circumference.

\section{Declarations}

\section{Acknowledgements}

We would like to express our appreciation to the nurses in each school health center and class teachers, who acted as the coordinator for data collection and anthropometric measurements.

\section{Authors' contributions}

$\mathrm{CHL}$ and PWW conceived the research question, analyzed data and wrote the manuscript. YWL, YTC and WTL conducted data analysis and edited the manuscript. ST, TMY, CYL and WCT helped with data collection. HLH and DWS contributed to data interpretation and reviewed the manuscript. All authors read and approved the final version of the manuscript.

\section{Funding}

This research work was supported by the Taiwan Ministry of Science and Technology (MOST 103-2314-B-037-019-MY3, MOST 106-2314-B-037-021-MY3, and MOST 109-2314-B-037-070 -MY3).

Availability of data and materials 
The datasets used and/or analyzed during the current study are available from the corresponding author on reasonable request.

\section{Ethics approval and consent to participate}

This study was approved by the Institutional Review Board of Kaohsiung Medical University. All participants and their parents/guardians provided signed informed assent and consent for the investigation.

\section{Consent for publication}

Not applicable.

\section{Competing interests}

The authors declare that they have no competing interests.

\section{References}

1. Berenson GS, Srinivasan SR, Bao W, Newman WP, 3rd, Tracy RE, Wattigney WA: Association between multiple cardiovascular risk factors and atherosclerosis in children and young adults. The Bogalusa Heart Study. N Engl J Med 1998, 338(23):1650-6.

2. DeBoer MD: Assessing and managing the metabolic syndrome in children and adolescents. Nutrients 2019, $11(8): 1788$.

3. Morrison JA, Friedman LA, Gray-McGuire C: Metabolic syndrome in childhood predicts adult cardiovascular disease 25 years later: the Princeton Lipid Research Clinics Follow-up Study. Pediatrics 2007, 120(2):340-5.

4. Morrison JA, Friedman LA, Wang P, Glueck CJ: Metabolic syndrome in childhood predicts adult metabolic syndrome and type 2 diabetes mellitus 25 to 30 years later. J Pediatr 2008, 152(2):201-6.

5. Magnussen CG, Koskinen J, Chen W, Thomson R, Schmidt MD, Srinivasan SR, Kivimaki M, Mattsson N, Kahonen M, Laitinen T et al: Pediatric metabolic syndrome predicts adulthood metabolic syndrome, subclinical atherosclerosis, and type 2 diabetes mellitus but is no better than body mass index alone: the Bogalusa Heart Study and the Cardiovascular Risk in Young Finns Study. Circulation 2010, 122(16):1604-11.

6. Steinberger J, Daniels SR, Eckel RH, Hayman L, Lustig RH, McCrindle B, Mietus-Snyder ML, American Heart Association Atherosclerosis H, Obesity in the Young Committee of the Council on Cardiovascular Disease in the $\mathrm{Y}$, Council on Cardiovascular $\mathrm{N}$ et al: Progress and challenges in metabolic syndrome in children and adolescents: a scientific statement from the American Heart Association Atherosclerosis, Hypertension, and Obesity in the Young Committee of the Council on Cardiovascular Disease in the Young; Council on Cardiovascular Nursing; and Council on Nutrition, Physical Activity, and Metabolism.

Circulation 2009, 119(4):628-47.

7. Martinez-Vizcaino V, Ortega FB, Solera-Martinez M, Ruiz JR, Labayen I, Eensoo D, Harro J, Loit HM, Veidebaum T, Sjostrom M: Stability of the factorial structure of metabolic syndrome from childhood to adolescence: a 6-year follow-up study. Cardiovasc Diabetol 2011, 10:81.

8. Goodman E, Daniels SR, Meigs JB, Dolan LM: Instability in the diagnosis of metabolic syndrome in adolescents. Circulation 2007, 115(17):2316-22.

9. Stanley TL, Chen ML, Goodman E: The typology of metabolic syndrome in the transition to adulthood. J Clin Endocrinol Metab 2014, 99(3):1044-52.

10. Chan TF, Lin WT, Huang HL, Lee CY, Wu PW, Chiu YW, Huang CC, Tsai S, Lin CL, Lee CH: Consumption of sugar-sweetened beverages is associated with components of the metabolic syndrome in adolescents. Nutrients 2014, 6(5):2088-103.

11. Kim S, So WY: Prevalence of metabolic syndrome among Korean adolescents according to the National Cholesterol Education Program, Adult Treatment Panel III and International Diabetes Federation. Nutrients 2016, 8(10):588.

12. Song P, Yu J, Chang X, Wang M, An L: Prevalence and correlates of metabolic syndrome in Chinese children: The China Health and Nutrition Survey. Nutrients 2017, 9(1):79.

13. Gaston SA, Tulve NS, Ferguson TF: Abdominal obesity, metabolic dysfunction, and metabolic syndrome in U.S. adolescents: National Health and Nutrition Examination Survey 2011-2016. Ann Epidemiol 2019, 30:30-6.

14. Lin WT, Lee CY, Tsai S, Huang HL, Wu PW, Chin YT, Seal DW, Chen T, Chao YY, Lee CH: Clustering of metabolic risk components and associated lifestyle factors: A nationwide adolescent study in Taiwan. Nutrients 2019, 11(3):584.

15. Liu CY, Hung YT, Chuang YL, Chen YJ, Weng WS, Liu JS, Laing KY: Incorporating development stratification of Taiwan townships into sampling design of large scale health interview survey. J Health Manag 2006, 4(1):1-22.

16. The WHO STEPwise approach to noncommunicable disease risk factor surveillance. Section 4: Guide to Physical Measurements (Step 2). Availabale online: https://www.who.int/ncds/surveillance/steps/Section\%204\%20Step\%202\%20Physical\%20Measurements.pdf (accessed on 17 Augest 2021). In.

17. Lin WT, Huang HL, Huang MC, Chan TF, Ciou SY, Lee CY, Chiu YW, Duh TH, Lin PL, Wang TN et al: Effects on uric acid, body mass index and blood pressure in adolescents of consuming beverages sweetened with high-fructose corn syrup. Int J Obes (Lond) 2013, 37(4):532-9. 
18. Lin WT, Chan TF, Huang HL, Lee CY, Tsai S, Wu PW, Yang YC, Wang TN, Lee CH: Fructose-rich beverage intake and central adiposity, uric acid, and pediatric insulin resistance. J Pediatr 2016, 171:90-6 e1.

19. Allain CC, Poon LS, Chan CS, Richmond W, Fu PC: Enzymatic determination of total serum cholesterol. Clin Chem 1974, $20(4): 470-5$.

20. Zimmet P, Alberti KG, Kaufman F, Tajima N, Silink M, Arslanian S, Wong G, Bennett P, Shaw J, Caprio S et al: The metabolic syndrome in children and adolescents - an IDF consensus report. Pediatr Diabetes 2007, 8(5):299-306.

21. The statement of Taiwan Pediatric Association for child and adolescent metabolic syndrome. Taiwan Pediatric Association, June 2016. Availabale online: https://www.pediatr.org.tw/people/edu_info.asp?id=33 (accessed on 17 Augest 2021).

22. Lin WT, Lin PC, Lee CY, Chen YL, Chan TF, Tsai S, Huang HL, Wu PW, Chin YT, Lin HY et al: Effects of insulin resistance on the association between the circulating retinol-binding protein 4 level and clustering of pediatric cardiometabolic risk factors. Pediatr Diabetes 2018, 19(4):611-21.

23. Wu PW, Tsai S, Lee CY, Lin WT, Chin YT, Huang HL, Seal DW, Chen T, Lee CH: Contribution of insulin resistance to the relationship between sugarsweetened beverage intake and a constellation of cardiometabolic abnormalities in adolescents. Int J Obes (Lond) 2021, 45(4):828-39.

24. Altman DG: Practical statistics for medical research. London, UK: Chapman and Hall; 1991.

25. Landis JR, Koch GG: The measurement of observer agreement for categorical data. Biometrics 1977, 33(1):159-74.

26. Rothman K, Greenland S: Modern epidemiology, 2nd edition edn. Philadelphia: Lippincott Williams \& Wilkins; 1998.

27. Lee CH, Lee KW, Fang FM, Wu DC, Tsai SM, Chen PH, Shieh TY, Chen CH, Wu IC, Huang HL et al: The neoplastic impact of tobacco-free betel-quid on the histological type and the anatomical site of aerodigestive tract cancers. Int J Cancer 2012, 131(5):E733-43.

28. Shulman Gl: Ectopic fat in insulin resistance, dyslipidemia, and cardiometabolic disease. N Engl J Med 2014, 371(23):2237-8.

29. DeBoer MD, Gurka MJ, Woo JG, Morrison JA: Severity of the metabolic syndrome as a predictor of type 2 diabetes between childhood and adulthood: the Princeton Lipid Research Cohort Study. Diabetologia 2015, 58(12):2745-52.

30. Gurka MJ, Golden SH, Musani SK, Sims M, Vishnu A, Guo Y, Cardel M, Pearson TA, DeBoer MD: Independent associations between a metabolic syndrome severity score and future diabetes by sex and race: the Atherosclerosis Risk In Communities Study and Jackson Heart Study. Diabetologia 2017, 60(7):1261-70.

31. DeBoer MD, Filipp SL, Sims M, Musani SK, Gurka MJ: Risk of ischemic stroke increases over the spectrum of metabolic syndrome severity. Stroke 2020, 51(8):2548-52.

32. Magnussen CG, Koskinen J, Juonala M, Chen W, Srinivasan SR, Sabin MA, Thomson R, Schmidt MD, Nguyen QM, Xu JH et al: A diagnosis of the metabolic syndrome in youth that resolves by adult life is associated with a normalization of high carotid intima-media thickness and type 2 diabetes mellitus risk: the Bogalusa heart and cardiovascular risk in young Finns studies. J Am Coll Cardiol 2012, 60(17):1631-9.

33. Huh JH, Ahn SG, Kim Yl, Go T, Sung KC, Choi JH, Koh KK, Kim JY: Impact of longitudinal changes in metabolic syndrome status over 2 years on 10-year incident diabetes mellitus. Diabetes Metab J 2019, 43(4):530-8.

34. Itoh H, Kurihara I, Miyashita K, Tanaka M: Clinical significance of 'cardiometabolic memory': a systematic review of randomized controlled trials. Hypertens Res 2017, 40(6):526-34.

\section{Supplementary Files}

This is a list of supplementary files associated with this preprint. Click to download.

- CarDMMetSTransformationsupplementarydata.pdf 